\title{
Cursos de Português para imigrantes na cidade de São Paulo - Ações locais de acolhimento à luz da Educação Social
}

\author{
Portuguese Classes for Immigrants in the City of São Paulo - local welcoming \\ actions from a social education perspective
}

Adriana de Carvalho Alves 1

\begin{abstract}
Resumo
No contexto do capitalismo globalizado do século XXI, os fluxos migratórios internacionais apresentam diversas matizes e especificidades dadas pelo contemporâneo e, por esse motivo demandam, por parte dos países receptores, a construção de ações locais que assegurem condições para o pleno exercício da cidadania, uma vez que o ato de migrar, independentemente da situação migratória vivenciada pelo sujeito, deve estar acompanhado da efetivação de direitos, que garantam a dignidade humana, conforme orientações dos organismos internacionais. Compreendendo que a aprendizagem da Língua Portuguesa é uma das etapas fundamentais para a participação na vida social, nos propomos a investigar os cursos que são oferecidos a esse público, estabelecendo relação entre essas práticas educativas e o referencial teórico da Educação Social, especialmente fundamentada nas ideias de Paulo Freire. O presente artigo apresenta o resultado de pesquisas de campo realizadas nos cursos de Lingua Portuguesa para Imigrantes oferecidos na cidade de São Paulo, por três organizações - SEFRAS/CRAI, EMEF Infante Dom Henrique e CAMI- nas quais pudemos observar o perfil das/os educadoras/os e do público que participa das aulas, os materiais e metodologia das aulas e as características das instituições.
\end{abstract}

Palavras-chave: Educação para Imigrantes. Educação Social. Direitos Humanos e Cidadania. Fluxos Migratórios Contemporâneos.

\section{Abstract}

In the context of the twenty-first century globalized capitalism, international migratory flows present different nuances and specificities

\footnotetext{
${ }^{1}$ Doutoranda pelo programa de "Educação, Arte e História da Cultura" (em curso), Universidade Presbiteriana Mackenzie, com pesquisa relacionada ao acolhimento de estudantes imigrantes na rede pública de ensino de São Paulo. Mestre em Integração da América Latina (2013), PROLAM/USP, com dissertação relacionada aos povos originários do Brasil e Argentina. Professora da Rede Municipal de Ensino de São Paulo desde 2002, tendo atuado em Educação Infantil em CEI e EMEI (2002-2012), e atualmente é professora de Ensino Fundamental II e Médio, História, E-mail: andritsena@hotmail.com
} 
from the contemporary, thus, for this reason, these flows demand, from the host countries, the setting up of local actions that ensure the full advantages of citizenship. Regardless the migratory situation experienced, it must consider how the rights must be increasingly applied to ensure their rights to guarantee human dignity, according to the guidelines of international organizations. Understanding Portuguese instruction is one of the fundamental stages for participation in social life, we propose to investigate the courses that are offered to this public, establishing a relationship between these educational practices and the theoretical reference of Social Education, especially based on Paulo Freire ideas. This article presents the results of field research conducted in Portuguese language courses for immigrants offered in São Paulo city by three organizations - SEFRAS / CRAI, EMEF Infante Dom Henrique and CAMI. In this experiment, we were able to observe the profile of educators, the public that participates in the classes, the materials, the approach and the characteristics of the institutions.

Keywords: Education for Immigrants. Social Education. Human Rights and Citizenship. Contemporary Migration Flows.

\section{INTRODUÇÃO}

A mobilidade humana sobre o planeta não é tema novo, contudo, no alvorecer do século XXI, esse fenômeno emerge enquanto uma das 'grandes preocupações' do mundo globalizado, envolvido em discursos que geralmente negam o direito ao deslocamento para alguns grupos, que impõe barreiras e aponta para a existência de alguns 'riscos' colocados pelos fluxos migratórios contemporâneos. Tratar do tema das migrações a partir da barreira da língua também não é novidade e o historiador Eric Hobsbawm, ao se referir aos processos de deslocamento entre os anos de 1870 e 1914, estabelece o domínio linguístico como elemento de reconhecimento e ascensão social, especialmente para as populações oriundas da Europa Oriental que se deslocavam para as mais diversas regiões do globo no período analisado pelo autor e, entre essas, o continente americano. O domínio da língua materna é, para o historiador, importante, porém, seu uso já não cumpre a função de distinguir culturalmente um indivíduo uma vez que, noutras partes do mundo, o 
monolinguísmo não oferece vantagens, colocando-se como um obstáculo para o desenvolvimento social e econômico.

A frieza dos novos tempos exigia o domínio - tanto na fluência quanto na escrita - de uma 'língua universal' pois a grande massa de trabalhadores teria mais vantagens caso dominassem uma língua de circulação ampla pois, 'em outros lugares, estaria um pouco melhor que um animal estúpido: um fardo de músculos mudos” (HOBSBAWN, 2004, p. 139). Diante da possibilidade de coisificação do humano nos tempos 'modernos', causada pela mudez que o reduz à músculos e meros instrumentos de trabalho, propomos a reflexão sobre a importância do aprendizado da Língua Portuguesa por parte das populações que constituem os fluxos migratórios contemporâneos na cidade de São Paulo. Essa reflexão se dará à luz do referencial teórico concernente à Educação Social, pautado na compreensão de que o acesso ao processo educativo é um mecanismo que auxilia no resgate à dignidade humana, perante uma realidade econômica e social excludente, sendo a exclusão, uma marca do sistema Capitalista contemporâneo.

\section{1-REFERENCIAL TEÓRICO}

Os fluxos migratórios contemporâneos demandam, por parte dos países receptores, a construção de ações locais que assegurem condições plenas para o exercício da Cidadania e, nesse aspecto, o aprendizado da Lingua Portuguesa é uma das etapas fundamentais para a participação na vida social. A Imigração é uma característica constitutiva da cultura de São Paulo, posto que imigrantes europeus e asiáticos estão, reconhecidamente, entranhados na história da cidade através de um processo migratório que se intensificou a partir da segunda metade do século XIX. Esse fluxo migratório, descrito na bibliografia especializada como "histórico" constitui a narrativa paulistana "moderna" e contribuiu para a ampliação do quadro demográfico e o alargamento da perspectiva 
da pluralidade cultural, consolidando a ideia do caráter multicultural de São Paulo e alterando a cartografia de sua narrativa.

Diferentemente do cenário do século XIX e início do XX, os fluxos contemporâneos são diversificados - se considerarmos que as migrações históricas foram compostas majoritariamente por europeus -, os novos contingentes são formados por migrantes regionais - oriundos de diversos países latino-americanos -, caribenhos e africanos. Um levantamento realizado pelo IPPDH/Mercosur apresenta os dados da Polícia Federal em relação as dez nacionalidades mais expressivas na capital paulista e revelam que os latino-americanos são cerca de $33,2 \%$ dos imigrantes registrados na cidade de São Paulo, sendo seguidos por europeus, representando cerca de $29,6 \%$ e de asiáticos, com 19,4\% ${ }^{2}$. A diversificação dos fluxos migratórios contemporâneos em São Paulo inaugurou uma outra relação entre a comunidade local e os imigrantes ${ }^{3}$, que, apesar de reivindicar sua origem imigrante e trazer esses elementos na sua narrativa identitária, tem colocado algumas barreiras em relação ao acolhimento dos novos cidadãos que se somam à cidade. Há um discurso vinculado, especialmente, à inquietude, e ao medo do que esses imigrantes representam para a sociedade local.

Em Confiança e medo na cidade, na qual Bauman (2009) faz apontamentos sobre a constituição da cidade moderna e globalizada, está presente a reflexão sobre os Estrangeiros e, para o sociólogo, estes são convertidos em simbolos das "forças inquietantes da globalização" mas, nem por isso, são bem vindos e acolhidos de forma positiva sendo, por outro lado, considerados 'mensageiros de desventuras', fazendo com que

\footnotetext{
${ }^{2}$ O Instituto de Politicas Públicas en Derechos Humanos del MERCOSUR, IPPDH, publicou em janeiro de 2017, o Relatório Migrantes Regionales en la ciudad de San Pablo: Derechos sociales y Politicas Públicas, com o propósito de apresentar o mapeamento das principais barreiras no acesso aos direitos sociais por parte da população imigrante regional e as ações desenvolvidas no âmbito do município de São Paulo para garantir o acesso a esses direitos.

${ }^{3}$ Para os fins desse estudo, utilizamos o termo Imigrante para se referir a pessoas que se deslocaram de seu país de origem e residem em São Paulo, não os diferenciando por sua condição migratória ou tipos de visto.
} 
os habitantes da cidade se recordem que o mundo 'moderno' e 'globalizado' segue em guerra, que apesar do marcante desenvolvimento industrial e tecnológico, existem pessoas desempregadas, vivendo em condições degradantes, sendo perseguidas por opiniões politicas, étnicas e religiosas, entre outas causas. Para o autor, conviver com estrangeiros traz à memória social "a fragilidade e a precariedade da condição humana e ninguém quer se lembrar dessas coisas horriveis todos os dias, coisas que prefeririamos esquecer" (BAUMAN, 2009, p. 80).

Esse 'medo' que circunda o imaginário social em relação aos imigrantes - e é seletivo tendo como estruturantes o elemento raça, etnia, religião e classe social - na maior parte do tempo está latente e pode ser percebido principalmente através do temor de uma suposta 'invasão de africanos' em São Paulo, contudo, em algumas situações, o medo se manifesta através da xenofobia praticada contra as comunidades consideradas 'indesejáveis'. Ao analisarmos o histórico das Politicas Migratórias no Brasil, verificamos que, em fins do século XIX e começo do XX, foram estabelecidos alguns critérios para regulamentar o ingresso de imigrantes no país, sendo estes categorizados em espontâneos, subsidiados ou indesejáveis. Os imigrantes indesejáveis, de acordo com o Decreto $\mathrm{n}^{\circ}$ 6.455, de 19 de abril de 1907, eram "as populações e indivíduos, que a partir de critérios de raça, convicções politicas, condições de saúde e de trabalho, características nacionais apresentavam comportamentos agressivos, inassimiláveis e perigosos a segurança nacional" (MAZZA, 2016, p. 236). Considerando as características das populações que são alvo de xenofobia na cidade, é possivel afirmar que as categorizações sociais estabelecidas no século XIX permanecem nos dias atuais, configurando-se enquanto uma continuidade histórica corporeificada através dos discursos em relação aos imigrantes recentemente chegados ao Brasil. Ao tratar da relação entre a identidade nacional, na perspectiva dos impactos da globalização sobre o movimento e mobilidade humanas, Hobsbawm (2007, p. 95) 
considera a xenofobia como donatária de uma crise que se funda no 'contemporâneo', ocasionada pela expectativa da percepção do papel dos Estados Nacionais como definidores de uma pretensa identidade e

\begin{abstract}
Não obstante $[\ldots]$ a xenofobia também reflete a crise de uma identidade nacional culturalmente definida no contexto dos Estados Nacionais, nas condições de acesso universal à educação e à informação e em uma época em que a política das identidades coletivas exclusivas, sejam étnicas, religiosas ou de gênero e estilo de vida buscam a regeneração de uma Gemeinschaft (comunidade) em uma Gesellchaft (sociedade) cada vez mais remota.
\end{abstract}

Esse desejo remoto - de regeneração da comunidade e sociedade seria, de acordo com o autor, propulsores das práticas xenofóbicas. No mundo contemporâneo é possivel alinhavar duas percepções distintas no que se refere aos fluxos. Por um lado, persiste a capitalismo globalizado regida pelo ideário dos mercados livres e, por outro, o fracasso do estabelecimento da livre movimentação internacional da força de trabalho (HOBSBAWM, 2007, p. 92), o que equivale a dizer que o mundo contemporâneo permite a livre circulação de bens, capitais e mercadorias, mas o mesmo não ocorre com a mobilidade humana. Ao Capital não há barreiras e, para as pessoas, se constroem muros. E os muros, sejam eles simbólicos ou de concreto, são construídos em territórios de fronteira (físicas e epistêmicas) no intuito de impedir que pessoas usufruam da cidade.

\title{
Imigração: movimento de caráter global que requer a construção de ações locais
}

Apesar de o tema das migrações ser um fenômeno global, é na cidade que o direito a migrar se efetiva e, por esse motivo, refletir sobre a construção de ações locais de acolhimento é imperante no contexto da cidade que recebe e, nessa perspectiva, o Relatório do IPPDH/Mercosur salienta que 
El vinculo entre migraciones y ciudades es de gran importancia para el diseño y la implementación de politicas migratorias desde el enfoque de los derechos humanos. Pensar las migraciones desde la perspectiva de las ciudades implica trasladar la mirada desde el Estado nacional hacia los Estados locales. [...] Las ciudades constituyen un espacio privilegiado para el estudio de las dinámicas y los resultados de las diversas formas de migración y movilidad. Estudiar las migraciones desde la perspectiva de las ciudades desplaza el interés de las razones de la movilidad de las personas hacia la determinación de las formas en que éstas trabajan, viven y configuran hábitats locales. (IPPDH, 2016, p. 15).

O documento aponta ainda que é na cidade onde se estabelecem as complexas relações entre a globalização, os processos de integração regional e as políticas públicas e, nesse sentido, nos propomos a investigar o acesso aos direitos sociais tendo como ponto de partida a oferta de cursos de Lingua Portuguesa destinados a atender as populações imigrantes na cidade de São Paulo. Nosso referencial teórico, ao tratar das ofertas educativas, é o que propõe Educação Social, compreendida como um campo conceitual que aglutina diversas formas de atendimento educativo a populações suscetiveis as mais variadas formas de vulnerabilidade social e, por essa razão, ocorre em contextos sociais diferenciados sendo estritamente vinculada à realidade de exclusão, marginalização e conflito social, desvio e abandono (SOUZA NETO, 2010, p. 32). Acreditamos que as populações imigrantes, especialmente relativas aos fluxos migratórios contemporâneos, encontram-se no perfil de atendimento da Educação Social especificamente porque, na maioria das vezes, estão invisibilizadas no tecido social, sendo essa invisibilidade o que acarreta na negação de direitos. Essa condição de exclusão se agrava principalmente entre os imigrantes indocumentados e, de acordo com a pesquisadora Giovanna Modé Magalhães

Estar em condição irregular num determinado país significa viver na ilegalidade sob o constante risco de deportação, já que o direito de emigrar não assegura o direito de entrar em outro país - processo esse que deve ser autorizado pelos Estados 
nacionais. Porém, o fato de lá estar não tira, do indivíduo ou do grupo, direitos fundamentais inerentes à condição humana, e entre eles os direitos educativos (2010, p. 15).

Os direitos educativos devem ser garantidos pela cidade independentemente da condição migratória - através da construção de ações locais e o modo como tem se operado a garantia desse direito tem contado com a mobilização da sociedade civil que atuam junto as demandas das populações imigrantes. É muito elucidativo o texto de apresentação do Mapeamento dos cursos de Português para Imigrantes elaborado pela Coordenação de Políticas para Migrantes ${ }^{4}$ da Secretaria Municipal de Direitos Humanos e Cidadania de São Paulo. O documento, que tem o propósito de garantir o acesso a informações sobre ofertas educativas nessa modalidade de ensino, sistematizou os dados a partir do cadastramento das informações por parte dos próprios agentes dos movimentos sociais, que representam as instituições. Sobre a relevância do aprendizado da língua por parte dos imigrantes e do protagonismo da sociedade civil o documento aponta que

O ensino do idioma de português para imigrantes é uma demanda apresentada pelos imigrantes em diversas situações, como por exemplo, a $1^{\circ}$ Conferência Municipal de Políticas para Imigrantes e os Diálogos Sociais, e tem sido realizado majoritariamente por organizações da sociedade civil (associações, ONGs, igrejas, etc.) que cumprem o papel de contribuir com a inclusão dessa população na sociedade brasileira, a partir do maior conhecimento da lingua portuguesa e contato com as ideias, costumes, valores, cultura brasileiras.

Compreendendo o aprendizado da língua local como uma ferramenta de inclusão social, e que são as ações locais engendradas na cidade que garantirão a efetivação dos direitos - seja através da iniciativa da sociedade civil ou da formulação de politicas públicas por parte do Estado - colocamos como objeto de investigação os suportes que têm sido

\footnotetext{
${ }^{4}$ A Coordenação de Políticas para Migrantes, CPMig, foi criada no âmbito da Secretaria Municipal de Direitos Humanos e Cidadania de São Paulo em 27/05/2013, e tem a finalidade de implantar uma política municipal para imigrantes de forma transversal, Intersetorial e participativa.
} 
oferecidos aos Imigrantes para auxiliá-los na aprendizagem da Lingua Portuguesa. Para empreender tal pesquisa, realizamos a análise do mapeamento anteriormente citado, afim de selecionar alguns dos espaços educativos arrolados no documento, com o propósito de realizar uma vivência nas aulas, junto aos educandos e educadores.

\section{2- METODOLOGIA}

Para operacionalizar a estratégia da vivência em campo, optamos por visitar os espaços educativos circunscritos à região central da cidade de São Paulo, especificamente nos bairros do Pari, Bom Retiro e Canindé e estabelecemos contato com os responsáveis pelas instituições: CAMICentro de Apoio e Pastoral do Migrante, SEFRAS-CRAI e EMEF Infante Dom Henrique. O roteiro da visita incluiu conhecer o perfil dos educandos e dos educadores, as condições estruturais e pedagógicas para o desenvolvimento do processo ensino-aprendizagem e as expectativas dos educandos em relação ao curso. Verificamos ainda a disponibilidade de outras atividades, além dos cursos de Língua Portuguesa, os projetos pedagógicos dos cursos e os materiais didáticos utilizados nas aulas. As três vivências ocorreram entre os meses de março e abril de 2017, em período noturno (durante a semana) e diurno (domingo), períodos em que são ofertados os referidos cursos. Esse dado é importante porque contribui para identificar socialmente o perfil do público atendido: são trabalhadores. Uma característica que despertou nossa surpresa foi a diversidade de origens nacionais e culturais dos estudantes em alguns desses espaços, sendo esse um grande desafio para as instituições proponentes. As reflexões desencadeadas através das vivências e as características dos espaços estão sistematizadas a seguir. 


\subsection{Curso do SEFRAS}

O primeiro espaço visitado foi o SEFRAS, Serviço Franciscano de Solidariedade, em que o curso de Língua Portuguesa é oferecido pelo Projeto Andorinha, através de uma parceria entre o Núcleo Refazenda, o SEFRAS e o CRAI ${ }^{5}$. Durante a visita pudemos verificar que perfil dos educandos era composto majoritariamente por homens - entre os cerca de 50 estudantes, haviam apenas 4 mulheres, sendo que uma dessas estava acompanhada do companheiro. A idade dos participantes variava entre 20 e 50 anos e, de acordo com a coordenação do curso, tratam-se de migrantes recém-chegados ao Brasil, que geralmente desenvolvem atividades relacionadas ao comércio informal na região do Brás, sendo o local de moradia o bairro do Pari, nas proximidades do local onde o curso é oferecido.

A nacionalidade mais expressiva é composta por oriundos de Bangladesh, contudo, haviam estudantes da Síria, Haiti, Paquistão, Marrocos, Egito, Tunísia, Índia, Bolivia, Colômbia e Cuba. O curso é dividido em dois módulos (sendo que cada aula tem duração de 1h15), de acordo com o grau de aquisição linguística do estudante e tem uma duração de aproximadamente três meses, com carga-horária de $36 \mathrm{~h}$ em cada módulo.

Em relação aos educadores entrevistados, tanto a coordenadora quanto o professor são profissionais experientes na docência em cursos de Lingua Portuguesa para Estrangeiros, sendo que ambos cursam ou já concluíram pós-graduação (Mestrado) na área da Linguística, com pesquisas acadêmicas relacionadas ao ensino de Língua Portuguesa para Imigrantes. Do diálogo que estabelecemos com os educadores foi possivel verificar que existe a compreensão da relevância social do trabalho que eles desenvolvem, sendo comum a ambos o discurso de que o curso é

\footnotetext{
${ }^{5} \mathrm{O}$ Centro de Referência e Atendimento para Imigrantes (CRAI-SP), é um equipamento público municipal, criado em novembro de 2014, com o objetivo de promover o acesso a direitos e a inclusão social, cultural e econômica das pessoas migrantes no município.
} 
destinado a satisfazer as necessidades imediatas do aluno, como se apresentar, cumprimentar pessoas, procurar trabalho, ir à delegacia e hospital, pedir uma informação na rua, entre outras coisas, ressaltando que o domínio da Lingua Portuguesa é uma necessidade social.

Sobre a relação entre educador e aluno, pudemos perceber o estabelecimento de vínculo, o que permite, por exemplo, a correção dos equívocos na pronúncia, sendo esse ato recebido com naturalidade por parte dos estudantes, que compreendem no ato da correção um certo respeito ao seu processo educativo e que, à luz da pedagogia emancipatória percebemos nesta, uma postura que leva em conta o protagonismo do sujeito que aprende, não o vitimizando. Sobre esse tema, o professor nos relata que tem uma postura exigente quanto a realização das tarefas justamente para estimular os estudantes, para que superem suas dificuldades e essa rigorosidade pedagógica é um dos indícios do compromisso social do educador. Na obra Pedagogia da Autonomia, Paulo Freire considera que assumir-se como ser social e histórico é uma das tarefas mais importantes da prática educativa, sendo que é "[...] nas relações uns com os outros e todos com o professor ou professora que se ensaia a experiência profunda de assumir-se" (FREIRE, 2000, p. 46). Ao estimular a superação dos desafios, no sentido da apreensão do vocabulário e da fluência, coletivamente, podemos perceber que existe um investimento nas potencialidades dos estudantes pois é oportunizado, a um jovem de Bangladesh que fala bengali e inglês, por exemplo, exercitar a experiência do erro e do acerto - e quando um dos estudantes acertava a pronúncia correta de uma palavra, a sala inteira o aplaudia, atitude que pode ser compreendida como um estímulo ao estudante na superação de suas dificuldades.

A metodologia de ensino utilizada segue as referências conceituais relativas ao ensino de Língua Portuguesa como Língua de Acolhimento, sendo que a apostila de atividades foi desenvolvida pela coordenadora do curso e foi construída para atender as necessidades do público atendido 
e, por esse motivo, é objeto de alterações e revisões constantes antes do início da oferta de cada oferta do curso, adaptando conteúdos e abordagens. Esse indicador nos remete à questão da flexibilidade do material didático ao perfil do público que o utiliza.

No que se refere a expectativa dos educandos em relação ao curso, questionamos a coordenadora sobre a assiduidade e a participação - uma vez que notamos que a turma era numerosa e atendia prontamente as propostas do professor - e as hipóteses levantadas pela profissional foram as de que frequentar o curso era uma experiência bem mais significativa que o próprio aprendizado da lingua. Ir para a aula e participar das atividades implica em se encontrar com pessoas - compatriotas ou de outras nacionalidades - e estabelecer relações constituindo, assim, um círculo social mais amplo, além de ter onde ir às terças e quintas feiras à noite 6 . O que pudemos notar, a partir da vivência com aqueles estudantes, foi o tamanho desafio que a diversidade nos propõe enquanto experiência, o que nos leva a refletir sobre a dimensão global que um espaço educativo pode proporcionar.

\subsection{Curso da EMEF Infante Dom Henrique}

A Escola Municipal de Ensino Fundamental Infante Dom Henrique localiza-se no bairro do Canindé e atende, regularmente, uma demanda numerosa de estudantes imigrantes. O curso oferecido pela EMEF Infante Dom Henrique ${ }^{7}$ não está arrolado no mapeamento organizado ela

\footnotetext{
${ }^{6}$ De acordo com a coordenadora do curso, a maioria dos estudantes tem uma jornada de trabalho muito extensa e vive em habitações muito precárias, compartilhando quartos minúsculos e mal ventilados. Assistir as aulas no SEFRAS é uma possibilidade de vivenciar uma experiência de sociabilidade.

7 Em 2017 a EMEF Infante Dom Henrique tornou-se Membro das Escolas Associadas da UNESCO por conta da relevância do trabalho pedagógico junto aos alunos e famílias Imigrantes, sendo que as instituições associadas são reconhecidas por trabalharem para apoiar e colocar em prática a compreensão internacional, a paz, o diálogo intercultural, o desenvolvimento sustentável e a educação de qualidade. Para conhecer a trajetória dessa escola indicamos CARVALHO, Francione Oliveira. Território do
} 
Coordenação de Políticas para Migrantes contudo, a unidade educacional é reconhecida internacionalmente justamente pelo trabalho de acolhimento à comunidade imigrante e a oferta do curso Português e Cultura Brasileira para Estrangeiros aponta como uma das ações inovadoras dessa escola. O Projeto Pedagógico do curso, disponibilizado pelo diretor da unidade, afirma essa posição ao destacar que a oferta de atividade formativa destinada a comunidade escolar coaduna com o princípio do direito à educação extensivo à comunidade, não se restringindo somente aos alunos regularmente matriculados.

A metodologia do curso foi construída a partir de estudos recentes no campo do ensino da língua não materna, sendo caracterizados pela distribuição dos saberes em 'competências comunicativas' e o material didático utilizado nas aulas foi elaborado por uma pesquisadora do Centro de Linguas da FFLCH/USP e tem como proposta o estímulo à oralidade vinculada a situações comunicativas com as quais o estudante irá se deparar no contexto social.

Assim como no curso oferecido pelo SEFRAS, os alunos são oriundos de diversos países: Haiti, Angola, Congo, Moçambique, Síria, Macedônia, Colômbia, Bolívia e Palestina. Quando interrogado sobre o que estimulou a iniciativa em acolher um curso de Português para Imigrantes, o diretor da escola nos informou que o mesmo acontece na desde março de 2015, uma vez que a equipe trabalha na perspectiva da educação ao longo da vida e na percepção da escola enquanto espaço permanente de formação, nas suas múltiplas dimensões técnicopedagógica, política e cultural, dando sentido aos princípios do Projeto Político Pedagógico. Dessa forma, foram formadas, até o momento, quatro turmas. A partir de 2017, o curso foi reorganizado, de modo que foram instituídos módulos de dois meses, a fim de assegurar a evolução dos cursistas, com a continuidade assegurada até dezembro, sendo possivvel,

significado: a cultura boliviana e a interculturalidade na rede municipal de São Paulo. Revista Diversitas, São Paulo, Ano 3, n 4, p. 161-214, mar./set., 2015. 
também, permanecer no ano seguinte, a critério do cursista. Atualmente a carga-horária é de quatro horas semanais, com aulas às terças e quintas-feiras, das 19 h30 às 21 h30.

Durante a vivência, tivemos a oportunidade de conversar com um educando recém-chegado de Luanda, Angola. Ao ser questionado sobre os motivos que o fizeram procurar um curso de Lingua Portuguesa, sendo ele oriundo de um país lusófono, o mesmo respondeu que existe uma certa 'dificuldade' na comunicação entre ele e os brasileiros e que muitas vezes há uma interrupção abrupta da sua fala ao perceberem que ele é estrangeiro. Esse fato ilustra a discriminação em relação aos imigrantes de pele negra e origem africana. A esse respeito é interessante notar que, de acordo com os dados apresentados pelo Relatório do IPPDH/Mercosur, os portugueses constituem a nacionalidade mais numerosa tanto no Brasil, sendo 22,4\% (270.772 pessoas), quanto em São Paulo, sendo $18,6 \%$ (71.451 pessoas $)^{8}$, contudo, em nenhum dos três espaços educativos que visitamos fomos informados de haviam portugueses frequentando as aulas. Por outro lado, foi possivel mapear a presença de angolanos e moçambicanos, o que demonstra que, para esses imigrantes, a barreira da língua está colocada como elemento de distinção quando pensamos na conquista dos direitos sociais, sendo necessária a participação destes em cursos para assimilar o português brasileiro, não bastando falar português.

\subsection{Curso do Centro de Acolhida e Pastoral do Migrante - CAMI}

O curso Português e Cidadania: Capacitação de imigrante em Lingua Portuguesa é oferecidos pelo CAMI nas regiões da cidade onde se observa uma concentração de imigrantes. O espaço que visitamos foi a sede da instituição, no bairro do Bom Retiro, contudo, as aulas ocorrem

\footnotetext{
${ }^{8} \mathrm{IPPDH} /$ Mercosur. op. cit. p. 20-23.
} 
também dos bairros do Brás, Belenzinho, Vila Maria Alta, Casa Verde, Jardim Brasil - com duas turmas-, Jardim Fontales e na cidade de Carapicuíba, concomitantemente e em parceria com diversas instituições sociais, religiosas e escolas públicas.

O programa do curso $^{9}$ salienta o que está explicitado em sua nomenclatura e oferece uma formação voltada para a formação cidadã, sendo que esse propósito é ressaltado dentre os objetivos, sendo estes: fornecer cursos de formação humana com enfoque nas perspectivas da Sociologia (especialmente na construção das relações sociais), da História (compreensão do contexto contemporâneo brasileiro), e do Direito (na formação de políticas públicas sociais) e da Espiritualidade (tolerância abertura para os outros) e Reciprocidade (expectativa de comportamento positivo, motivado pelo altruísmo e pela confiança).

Em consonância com essa proposta de formação mais ampla que o aprendizado da língua, a metodologia do curso prevê um diálogo constante com os educadores, de modo que os educandos possam dirimir suas dúvidas, a utilização de materiais didáticos que promovam a motivação e a inclusão dos estudantes na construção de sua trajetória de aprendizagem e estudos de meio em parques, museus, apresentações artísticas e outros equipamentos culturais da cidade de São Paulo. Além disso, fazem parte do roteiro de aprendizado a participação nos eventos e atividades das quais o CAMI participa ou organiza: Dia do trabalhador, Festival de Música e Poesia, Marcha dos Imigrantes, dia da Mãe LatinoAmericana, Celebrações Inter-religiosas, Assembleias Populares e Seminários.

O curso acontece aos domingos, das $10 \mathrm{~h}$ às $12 \mathrm{~h}$ sendo que, além da aula de Língua Portuguesa, é possivel ao educando participar de outros cursos promovidos pela instituição, como Informática, Música, Modelagem, Teatro e Eletricidade, que ocorrem em diferentes horários no mesmo espaço. A disponibilidade dessas atividades aos domingos

9 Disponivel em http://camimigrantes.com.br/site/?page_id=382. 
propicia aos imigrantes uma qualificação em outras áreas, que se diferem daquelas a que eles se dedicam durante a semana, possibilitando o alargamento das perspectivas profissionais.

Quando iniciamos nossa visita, havia um grupo de educandos participando da aula de música (canto e violão) e, em conversa com o professor, fomos informados que os estudantes estavam se preparando para uma apresentação na Catedral da Sé, onde fariam uma participação especial na missa do $1^{\circ}$ de maio. Cabe ressaltar que dos cerca de 60 alunos presentes na aula de português, a totalidade eram os hispanohablantes, e com uma representação feminina muito superior à que pudemos verificar nos demais espaços visitados.

O estímulo a participação ativa dos imigrantes em atividades que colocam em diálogo formação-participação política- cultura, numa perspectiva transversal, traz à tona as observações de Bonassi (2000) quando a autora reflete sobre a importância das atividades culturais para as comunidades imigrantes, uma vez que

[...] adquire importância a recuperação histórica dos processos culturais e a análise do popular que está registrado nesses processos, assim como é necessário superar o conceito de identidade nacional inculcado pelos governos nacionais nas barreiras entre os povos, e não a riqueza das diferenças culturais. (BONASSI, 2000, p. 186).

Para além do aprendizado da língua, a participação nos processos de produção cultural e social são fundamentais para o acolhimento das populações imigrantes em São Paulo e, nesse sentido, a oportunização de momentos coletivos, nos quais o educando poderá se socializar, questionar, apreender conceitos e produzir cultura são fundamentais para o processo formativo contínuo. Faz muito sentido, por exemplo, o relato que ouvimos de um dos profissionais que atua no CAMI, colombiano residente há 4 anos no Brasil e que percebe a necessidade da comunicação como elemento primordial para a circulação mais eficaz no espaço social. Para ele, uma das maiores dificuldades é compreender o que é dito nas ruas, pois o português ensinado no curso é aquele 
vinculado à norma culta, restrito a espaços sociais formais sendo que, nas ruas, as exigências são outras. Ao fazer essa observação, podemos compreender que o domínio da língua não se restringe a apropriação de vocábulos e ortografia, pois o repertório cultural é disponibilizado e apreendido a partir do contato entre imigrantes e brasileiros, sendo primordial o diálogo cultural.

\section{RESULTADOS}

Analisar os fluxos migratórios contemporâneos a partir da perspectiva das politicas de acolhimento em âmbito local possibilitou verificar algumas singularidades, o que contribui no sentido de romper com as generalizações construir um repertório conceitual e empírico que auxiliam a compreensão dos dilemas que o fenômeno dos fluxos migratórios contemporâneos ainda apresenta. $\mathrm{O}$ contexto da globalização promoveu uma grande quantidade de demandas sociais que o Estado não se preparou para atender, o que colocou alguns imigrantes em situação de extrema vulnerabilidade social. As politicas locais foram construídas a partir do que se considera "questões": a "questão" dos haitianos, a "questão" dos latino-americanos em trabalho escravo ou análogo a escravidão, a "questão" dos africanos que não sabem falar a língua... e para essas questões não resolvidas, ou não suficientemente compreendidas, as soluções mais fáceis são, geralmente, as mais perigosas, como a interposição de barreiras aos imigrantes e a culpabilização desses por sua condição de vulnerabilidade - "soluções" articuladas a um discurso racista e xenofóbico. A porosidade da fronteira permite o ingresso de capitais e mercadorias, mas apresenta impermeabilidade à circulação de culturas, cosmogonias, sonhos e expectativas de recomeços. A estruturação da sociedade brasileira, construída a partir de bases racistas e excludentes, contribui ao classificar socialmente sujeitos, hierarquizando-os a partir da percepção dos que seriam bem quistos, e aqueles as quais deveriamos fechar nossas 
fronteiras. Haitianos, latinos e africanos constituem um corpo social que causa estranheza na metrópole construída por muitos braços - inclusive migrantes e imigrantes. Conforme salientou Bonassi (2000, p. 186) a artificialidade das fronteiras sobrepõe-se a percepção da possibilidade dos fluxos culturais, através da constituição das barreiras nacionais e, nesse aspecto, sociólogo Anibal Quijano contribui ao atribuir ao capitalismo eurocentrado a base epistemológica na qual se fundaram as fronteiras.

Hoje, a luta contra a exploração/dominação implica, sem dúvida, em primeiro lugar, o engajamento na luta pela destruição da colonialidade do poder, não só para terminar com o racismo, mas pela sua condição de eixo articulador do padrão universal do capitalismo eurocentrado [...]. Isso significa a devolução aos próprios indivíduos, de modo direto e imediato, do controle das instâncias básicas de sua existência social: trabalho, sexo, subjetividade e autoridade. (QUIJANO, 2010, p. 26-27)

A partir da perspectiva de Quijano (2010) poderíamos compreender que a luta contra as formas de discriminação perpassa, quando nos referimos aos imigrantes, na aquisição da língua na medida em que é através da apropriação do português - e todo o conjunto simbólico, político e cultural que a aquisição desse aprendizado propicia - que o imigrante tem a possibilidade de recuperar a possibilidade de sonhar, de reassumir o controle de sua vida e de projetar seu porvir. Retomando as duras palavras de Hobsbawm (2004), com as quais começamos essa reflexão, não seria demasiado afirmar que é através dos cursos de Língua Portuguesa, oferecidos pelas instituições da sociedade civil, que o imigrante rompe com a condição de 'feixe de músculos mudo' e se converte em sujeito social. E nessa experiência de tomada de consciência e conversão em ser social, além da barreira da língua, as categorias de diferenciação social, tais como idade, Gênero, Etnia e Raça exercem uma influência significativa na conquista dos direitos sociais.

Nesse sentido, se nos centrarmos no recorte de gênero por exemplo, foram apresentadas, no decorrer da pesquisa, algumas inquietações, uma vez que a pouca presença de mulheres nos cursos de português para 
imigrantes que visitamos não reflete a realidade migratória presenciada e os dados sistematizados pelo Relatório do IPPDH/Mercosur dão conta de que existe um equilíbrio entre o ingresso de homens e mulheres no Brasil. A esse respeito, Tatiana Chang Waldman e Maria Angélica Beghini Morales contribuem para nossas reflexões através de um substancial trabalho, fruto de pesquisas relacionadas à História Oral, na qual evidenciam que as questões de gênero que pautam a atuação dos coletivos das mulheres imigrantes refletem os mesmos problemas enfrentados por todas as mulheres, inclusive as brasileiras. Contudo, esses problemas são agravados pela condição migratória sendo que "[...] nesses casos, por sua vez, somam-se à essas dificuldades, comuns ao gênero feminino, toda a seara de questões relacionadas ao seu deslocamento e os obstáculos e entraves na experiência de migrar" (WALDMAN; MORALES, 2016, p. 73). Acessar as ofertas formativas relativas à língua e à cidadania ainda se configura um obstáculo as mulheres imigrantes, contudo, existe forte mobilização por parte de coletivos feministas imigrantes, que buscam articulam a conquista por direitos e a superação do machismo.

Os cursos de Língua Portuguesa para imigrantes, com suas mais diversas especificidades e singularidades, contribuem para a tomada de consciência da condição de sujeitos sociais por parte dessa parcela da população, atuando na superação da barreira linguística e reafirmando o que Gadotti (2012, p. 29) propõe como sendo um dos sentidos do processo formativo, uma vez que “[...] educar para outros mundos possiveis é educar para superar a lógica desumanizadora do capital que tem no individualismo e no lucro seus fundamentos (...)". Podemos localizar a oferta desses cursos no amplo espectro que compõe a Educação Social na medida em que essa concepção se remete a atuação da sociedade civil, que imprime na sociedade suas marcas especialmente desvelando as diversas formas de exclusão e, para Gadotti (2012, p. 13) 
Trata-se de um paradigma teórico nascido no calor das lutas populares que passou por vários momentos epistemológicos e organizativos, visando não só à construção de saberes, mas também ao fortalecimento das organizações populares. Sem perder seus princípios, a educação popular vem se reinventando hoje, incorporando as conquistas das novas tecnologias, retomando velhos temas e incorporando outros: o tema das migrações, da diversidade, o lúdico, a sustentabilidade, a interdisciplinaridade, a intertransculturalidade, a questão de gênero, idade, etnia, sexualidade, desenvolvimento local, emprego e renda... mantendo-se sempre fiel à leitura do mundo das novas conjunturas.

As reflexões resultantes da vivência nos cursos, do diálogo com educadores e educandos e observação das dinâmicas sociais em que essa relação educativa ocorre, são elementos que indicam a vivacidade proporcionada pela prática da educação fortemente marcada pela compreensão do caráter emancipatório da prática pedagógica. Trata-se de um processo educativo entranhado nas demandas sociais e que articulam aspectos sociais e culturais à uma demanda histórica - os fluxos migratórios -, contribuindo para a construção de uma Educação alinhada as pautas contemporâneas.

\section{CONSIDERAÇÕES FINAIS}

A cidade de São Paulo do século XXI, reconhecida e identificada por seu caráter multicultural ainda carrega em si contradições relacionadas ao cenário do mundo globalizado, não sendo oferecidas a todos os cidadãos as plenas condições para seu desenvolvimento social, econômico e cultural, sejam brasileiros ou imigrantes e é justamente nessa fricção que atuam os movimentos populares, os coletivos e as instituições, que tomam para si a tarefa função de tensionar a aparente harmonia social, desvelando as desigualdades. A práxis social exercida nos espaços educativos que visitamos explicitam uma alternativa ao que salientou Bauman (2013, p. 71), ao criticar o Estado em sua função de provedor dos meios para o desenvolvimento dos cidadãos, abandonandoos à lógica do mercado, sendo que "a perniciosa fragilidade da condição 
social é agora redefinida como assunto privado, tema a ser tratado por indivíduos que utilizam recursos de sua propriedade pessoal". A vulnerabilidade social no século XXI, em São Paulo, é definida e estruturada pelos laços da colonialidade, através dos marcadores de Gênero, Raça, e Etnia e, por serem estes marcadores sistêmicos, não podem ser suprimidos através de uma atuação individual, mas através da atuação dos movimentos sociais, que recuperam o caráter coletivo da luta social.

Curiosamente um dos imigrantes que conhecemos nas vivências relatadas e com quem pudemos dialogar por alguns minutos, se chamava Benvindo.

\section{REFERÊNCIAS}

BAUMAN, Z. Confiança e medo na cidade. Rio de Janeiro: Zahar, 2009. . Danos Colaterais. Rio de Janeiro: Zahar, 2013.

BONASSI, M. Canta, América sem fronteiras: imigrantes latinoamericanos no Brasil. São Paulo: Edições Loyola, 2000.

FREIRE, P. Pedagogia da Autonomia: saberes necessários à prática educativa. 16. Ed. São Paulo: Paz e Terra, 2000.

GADOTTI, M. Educação Popular, Educação Social, Educação Comunitária: conceitos e práticas diversas, cimentadas por uma causa comum. Revista Diálogos: pesquisa em extensão universitária. IV Congresso Internacional de Pedagogia Social: domínio epistemológico. Brasília, v.18, n.1, dez, 2012.

IPPDH. Instituto de Políticas Públicas en Derechos Humanos del MERCOSUR. Migrantes Regionales en la ciudad de San Pablo: Derechos sociales y Políticas Públicas, 2017.

HOBSBAWM, E. Globalização, Democracia e Terrorismo. São Paulo: Companhia das Letras, 2007. Nações e Nacionalismo desde 1870: Programa, Mito e Realidade.

4. ed. São Paulo: Paz e Terra, 2004.

MAGALHÃES, G. M. Fronteiras do Direito Humano à Educação: um estudo sobre os imigrantes bolivianos nas escolas públicas de São Paulo. São Paulo, 2010. Dissertação (Mestrado em Educação). Universidade de São Paulo. MAZZA, D.; NORÕES, K. Educação e migrações internas e internacionais: um diálogo necessário. Jundiaí: Paco editorial, 2016. 
QUIJANO, A. Colonialidade do Poder e Classificação Social. In: SOUSA SANTOS, B. de. MENESES, M. P. Epistemologias do Sul. São Paulo: Cortez, 2010.

SOUZA NETO, J. C. de. Pedagogia Social: a formação do educador social e seu campo de atuação. Cadernos de Pesquisa em Educação PPGEUFES: Vitória, v. 16, no 32. p. 29-64. jul/dez. 2010.

WALDMAN, T. C.; MORALES, M. A. B. Mulheres em movimento: registrando memórias migrantes. In: Dossiê: rostos femininos na Imigração. Travessia - Revista do Migrante: São Paulo, n 78, p. 65-78. Jan./jun., 2016. 